\title{
Fuel Production from LDPE-based Plastic Waste over Chromium Supported on Sulfated Zirconia
}

\author{
Latifah Hauli, Karna Wijaya*, and Akhmad Syoufian \\ Department of Chemistry, Faculty of Mathematics and Natural Sciences, Universitas Gadjah Mada, \\ Sekip Utara, Yogyakarta 55281, Indonesia
}

*Corresponding author:

email: karnawijaya@ugm.ac.id

Received: May 9, 2019

Accepted: August 16, 2019

DOI: $10.22146 /$ ijc. 45694

\begin{abstract}
The preparation, characterization, and catalytic activity test of sulfated zirconia (SZ) modified with chromium for the hydrocracking of LDPE-based plastic waste have been investigated. SZ was prepared by wet impregnation method using zirconia nanopowder $\left(\mathrm{ZrO}_{2}\right)$ and $\mathrm{H}_{2} \mathrm{SO}_{4}$ solution. $\mathrm{SZ}$ was further modified with chromium (0.5, 1.0, and $1.5 \%$ wt.\%) by refluxing in aqueous solution of $\mathrm{Cr}\left(\mathrm{NO}_{3}\right)_{3} \cdot 9 \mathrm{H}_{2} \mathrm{O}$, followed by calcination and reduction processes. The prepared catalysts were characterized by SEMMapping and TEM. Hydrocracking of LDPE-based plastic waste was conducted at various temperatures and various catalysts. In addition, the optimum catalyst was repeatedly used for the reaction to demonstrate the stability of the catalyst. Liquid products obtained by hydrocracking were characterized by GCMS. The results showed that the morphology of the prepared catalysts had different sizes and disordered shapes after the addition of sulfate and Cr. The effective temperature for hydrocracking was $250{ }^{\circ} \mathrm{C}$. The highest selectivity to liquid product and gasoline fraction were 40.99 and $93.42 w t . \%$, respectively, and were obtained over Cr/SZ with 1.0 wt.\% Cr. Hydrocracking of plastic waste over the used Cr/SZ catalyst with $1.0 \mathrm{wt} . \% \mathrm{Cr}$ showed that the Cr/SZ catalyst was stable and reusable up to three repetitions.
\end{abstract}

Keywords: sulfated zirconia; chromium; catalyst; LDPE plastic; fuel

\section{- INTRODUCTION}

Hydrocracking is a method that can be used to overcome plastic waste-related problems [1]. It is wellknown that plastic wastes require a very long time to be naturally degraded [2]. In addition, burning plastic wastes has a dangerous impact because it can produce compounds that are potentially carcinogenic [3]. Hydrocracking can be carried out by thermal and catalytic methods. Thermal hydrocracking requires very high temperatures while catalytic hydrocracking is carried out using a catalyst at a relatively lower temperature. Recently, the catalyst which is widely developed for hydrocracking process is in the form of a metal oxide such as zirconia $\left(\mathrm{ZrO}_{2}\right)$ [4-6].

$\mathrm{ZrO}_{2}$ is a material that is often used as a catalyst in many studies. This material is very attractive due to its high thermal stability, low thermal conductivity, and its resistance to corrosion [7-10]. $\mathrm{ZrO}_{2}$ can be modified with sulfuric acid to increase its acidity. This modified product is called sulfated zirconia (SZ). Some applications such as hydrocracking, isomerization, and esterification usually require catalysts that have high acidity and, in this term, $\mathrm{SZ}$ is widely reported to be used as a catalyst [11-14]. The high acidity of SZ is caused by the presence of Brønsted and Lewis acid sites [15]. Catalytic properties of SZ can be determined from the modification method, sulfate agent, temperature of thermal treatment, and $\mathrm{ZrO}_{2}$ precursor [16]. The crystalline phase of SZ depends on the crystalline phase of the initial $\mathrm{ZrO}_{2}$ precursor used. It is known that $\mathrm{ZrO}_{2}$ has three crystalline phases namely monoclinic, tetragonal, and cubic phases. These phases are influenced by calcination temperature [17]. But in the $S Z$ case, very high temperatures can remove the sulfate groups from the catalyst [18]. In morphology, the particle shape of $\mathrm{SZ}$ can be affected by some factors such as $\mathrm{pH}$ of solution, the applied precursor, and the calcination 
temperature. The increase of calcination temperature can also increase the particle separation and decrease the size of the SZ particles. This factor tends to make SZ form particle agglomeration [9]. The presence of metal on SZ can promote particle agglomeration as reported by AboulGheit et al. [25]. However, it depends on the treatment process and the precursor used in the catalyst preparation.

Modification of SZ with metals can increase its catalytic activity and reduce coke formation [19]. Having high acidity, however, can cause SZ to suffer from deactivation due to the coke formation at high temperatures [20]. This deactivation can be overcome by modifying SZ with metals. Promotion of SZ with platinum has been widely reported as a catalyst that exhibits better catalytic activity [21]. However, platinum is very expensive. Alternatively, researchers use other transition metals to be impregnated to SZ. Amin et al. reported that the presence of $\mathrm{Ni}$ on $\mathrm{SZ}$ can diminish coke formation and enhance the catalytic activity in hydrocracking of plastic waste [22]. In addition, this enhancement gives high liquid product in the hydrocracking reaction. Thus, we expected that transition metals other than $\mathrm{Ni}$ would also have a positive impact on the catalytic performance for hydrocracking reactions. In this research, Cr was doped to $\mathrm{SZ}$ as a promoter. Since there are only a few reports on the application of $\mathrm{Cr} / \mathrm{SZ}$ for the hydrocracking of plastic waste, this research is expected to provide useful information about the catalyst activity and selectivity in the hydrocracking process.

\section{- EXPERIMENTAL SECTION}

\section{Materials}

$\mathrm{ZrO}_{2}$ nanopowder was purchased from Hongwu International Group Ltd. $\mathrm{H}_{2} \mathrm{SO}_{4} \quad$ (98\%) and $\mathrm{Cr}\left(\mathrm{NO}_{3}\right)_{3} \cdot 9 \mathrm{H}_{2} \mathrm{O}$ were purchased from Merck. Lowdensity polyethylene (LDPE) waste materials were collected from the final disposal site in Yogyakarta. $\mathrm{H}_{2}$ gas was supplied by PT. Samator Gas Industri.

\section{Procedure}

\section{Catalyst preparation and characterization}

Sulfated zirconia was obtained by wet impregnation method from $10 \mathrm{~g} \mathrm{ZrO}_{2}$ nanopowder material and $150 \mathrm{~mL}$ of $0.8 \mathrm{M} \mathrm{H}_{2} \mathrm{SO}_{4}$ solution. The sample was stirred for $24 \mathrm{~h}$, dried in an oven at $100^{\circ} \mathrm{C}$ for $24 \mathrm{~h}$, and calcined at $600^{\circ} \mathrm{C}$ for $4 \mathrm{~h}$, sequentially. The catalyst produced was labeled as SZ [23].

Chromium (0.5, 1.0, and 1.5 wt.\%) was added by reflux technique to the calcined $\mathrm{SZ}$ support using aqueous solution of $\mathrm{Cr}\left(\mathrm{NO}_{3}\right)_{3} \cdot 9 \mathrm{H}_{2} \mathrm{O}$ at $90^{\circ} \mathrm{C}$ for $4 \mathrm{~h}$. The obtained samples were dried in the oven at $100{ }^{\circ} \mathrm{C}$ for $24 \mathrm{~h}$, calcined at $600^{\circ} \mathrm{C}$ for $4 \mathrm{~h}$, and then reduced at $400^{\circ} \mathrm{C}$ for $3 \mathrm{~h}$ in $\mathrm{H}_{2}$ gas stream $(10 \mathrm{~mL} / \mathrm{min})$ [24]. The obtained catalysts were labeled as $\mathrm{Cr} 1 / \mathrm{SZ}, \mathrm{Cr} 2 / \mathrm{SZ}$, and $\mathrm{Cr} 3 / \mathrm{SZ}$ which correspond to $\mathrm{SZ}$ with $0.5,1.0$, and $1.5 \mathrm{wt} . \% \mathrm{Cr}$, respectively. Surface morphology of the catalysts was characterized by SEM-Mapping (JEOL, JSM-6510). The morphology of catalysts was also characterized by TEM (JEOL JEM-1400).

\section{Hydrocracking experiment}

Plastic pyrolysis was conducted at $300-400{ }^{\circ} \mathrm{C}$ for $4 \mathrm{~h}$ using a pyrolysis reactor (Fig. 1). The plastic was washed, dried, and cut into small pieces before being put into the reactor. The obtained liquid was hydrocracked by using a hydrocracking microreactor (Fig. 2). The catalyst sample was placed in the catalyst container while the pyrolysis product was in the feed container of the hydrocracking microreactor then the reaction was observed for $1 \mathrm{~h}$ with the feed/catalyst ratio of 100 in $\mathrm{H}_{2}$ gas stream $(10 \mathrm{~mL} / \mathrm{min})$. The catalytic activity and selectivity tests were done at various temperatures (250, 300 , and $\left.350{ }^{\circ} \mathrm{C}\right)$, using various catalysts $\left(\mathrm{ZrO}_{2}, \mathrm{SZ}\right.$, $\mathrm{Cr} 1 / \mathrm{SZ}, \mathrm{Cr} 2 / \mathrm{SZ}$, and $\mathrm{Cr} 3 / \mathrm{SZ}$ ), and over the reuse of the optimum catalyst. The type of plastic was investigated by FTIR (Shimadzu Prestige-21). The obtained liquid from

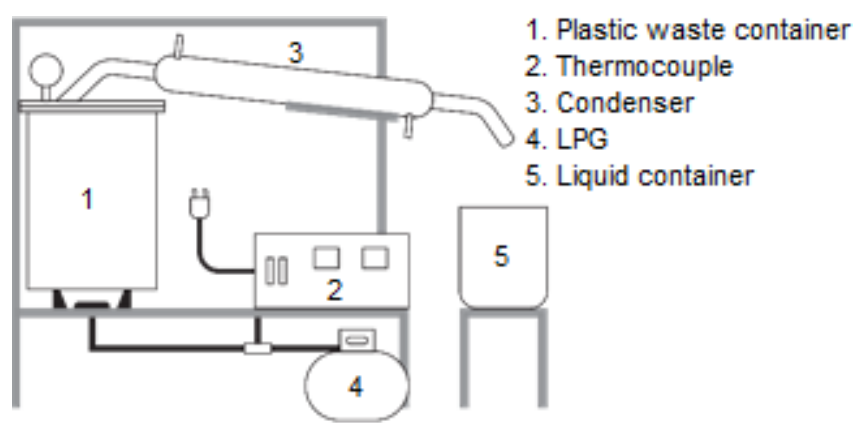

Fig 1. The schematic diagram of the plastic pyrolysis apparatus 


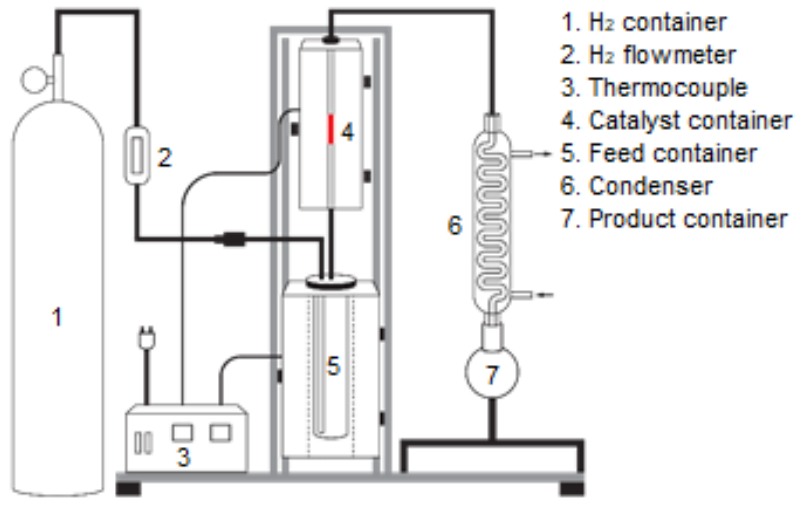

Fig 2. The schematic diagram of the hydrocracking microreactor

the hydrocracking process was characterized by GCMS
(Shimadzu QP 2010S). The conversion yield was calculated by using the following equations:

Liquid product $\left(\right.$ wt.\%) $=\frac{\text { weight of liquid product }}{\text { weight of feed }} \times 100 \% \quad$ (1)

Coke product $($ wt. $\%)=$

$$
\frac{\text { weight gain of catalyst hydrocracking }}{\text { weight of feed }} \times 100 \%
$$

Gas product $(\mathrm{wt} . \%)=100 \%-\mathrm{wt} . \%($ liquid + coke $)$

\section{- RESULTS AND DISCUSSION}

\section{Catalyst Characterization}

The SEM images of $\mathrm{ZrO}_{2}$, SZ, Cr1/SZ, Cr2/SZ, and $\mathrm{Cr} 3 / \mathrm{SZ}$ catalysts are presented in Fig. 3. SEM results

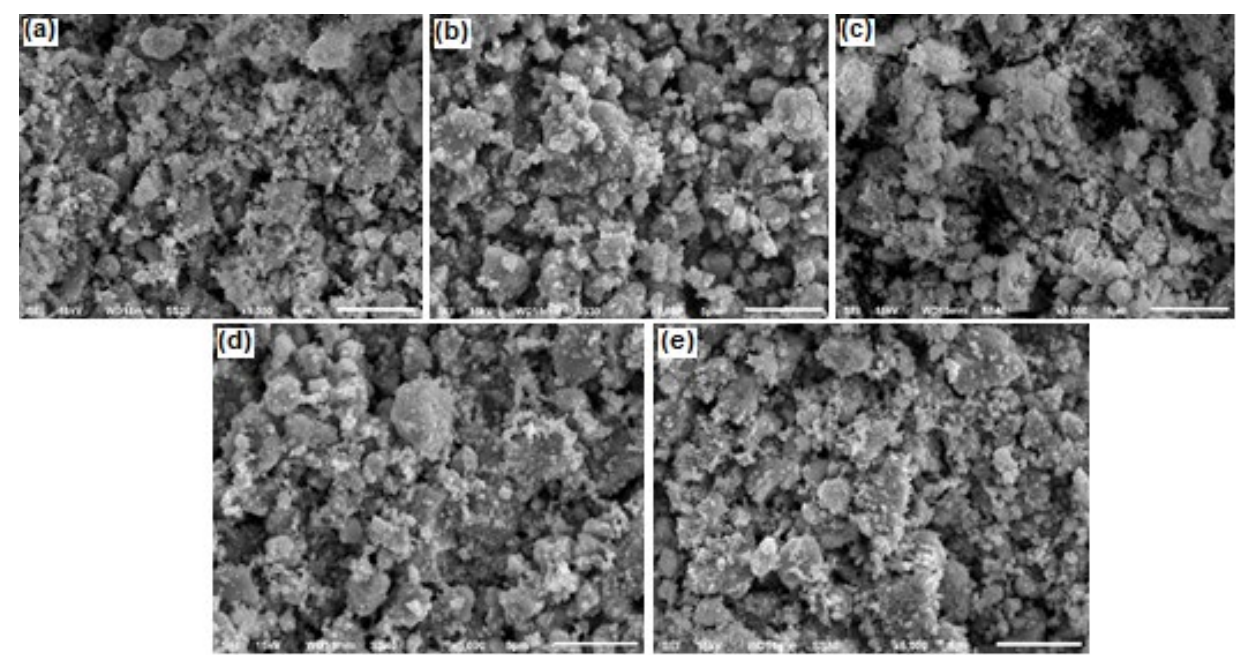

Fig 3. SEM images of (a) $\mathrm{ZrO}_{2}$, (b) $\mathrm{SZ}$, (c) $\mathrm{Cr} 1 / \mathrm{SZ}$, (d) $\mathrm{Cr} 2 / \mathrm{SZ}$, and (e) $\mathrm{Cr} 3 / \mathrm{SZ}$
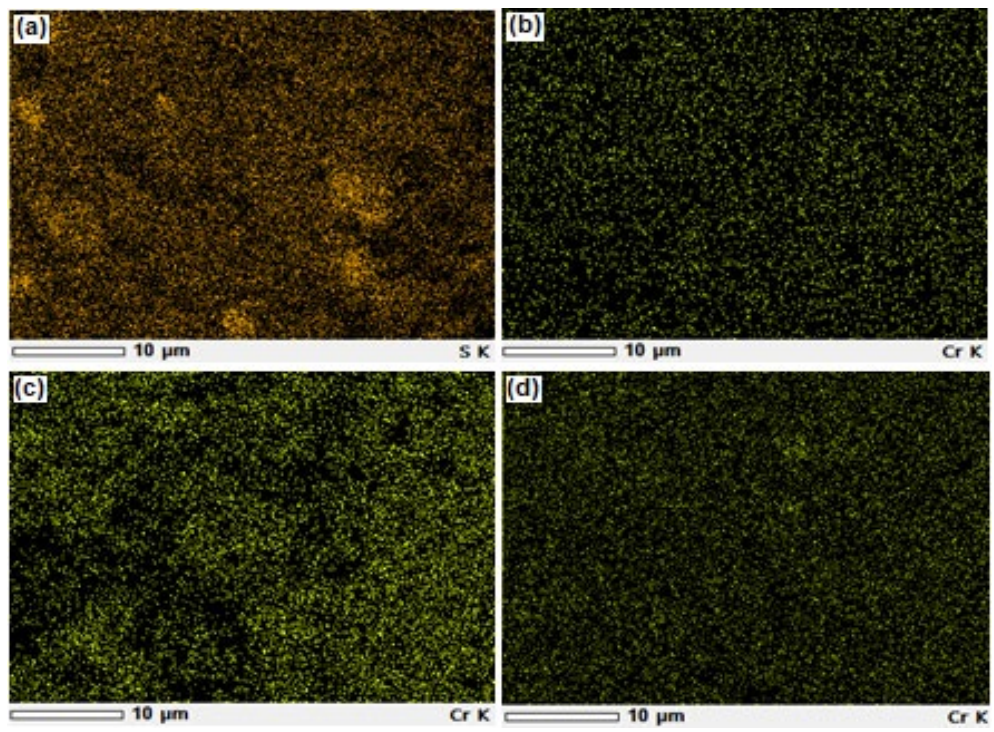

Fig 4. Mapping of (a) SZ, (b) Cr1/SZ, (c) Cr2/SZ, (d) Cr3/SZ 


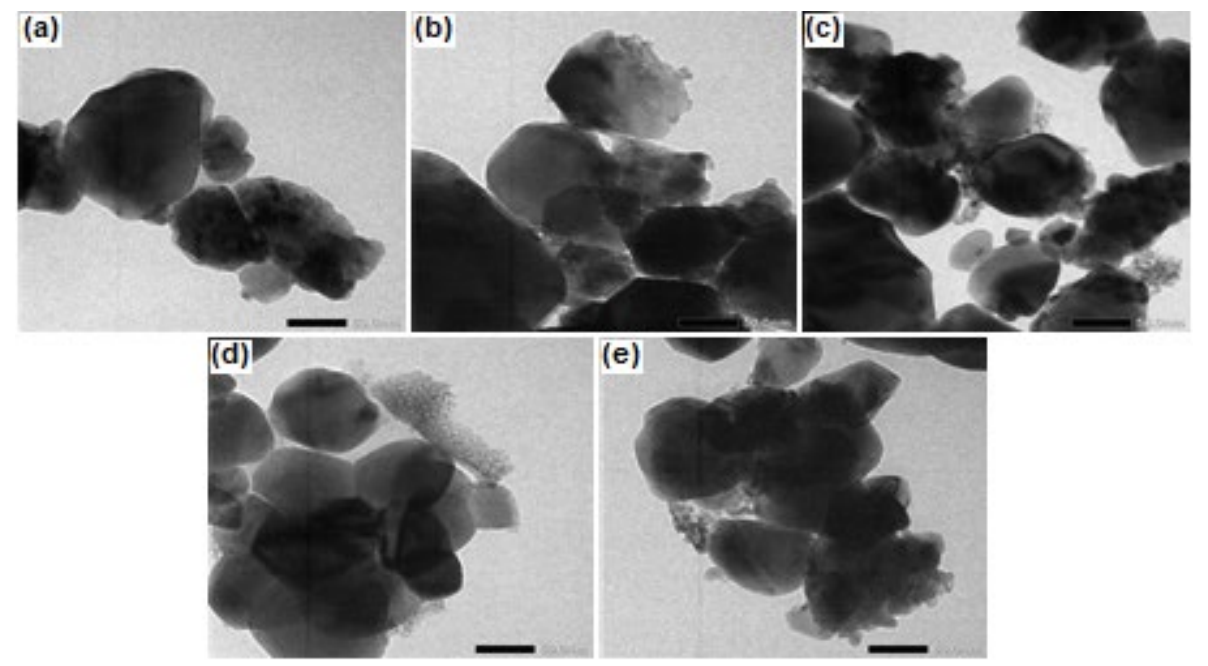

Fig 5. TEM images of (a) $\mathrm{ZrO}_{2}$, (b) $\mathrm{SZ}$, (c) $\mathrm{Cr} 1 / \mathrm{SZ}$, (d) $\mathrm{Cr} 2 / \mathrm{SZ}$, (e) $\mathrm{Cr} 3 / \mathrm{SZ}$

showed the particle agglomeration with different sizes and disordered shapes on the $\mathrm{ZrO}_{2}$ surface after the addition of sulfate and $\mathrm{Cr}$ [20]. This agglomeration was possible due to sulfate and $\mathrm{Cr}$ dispersion on the $\mathrm{ZrO}_{2}$ surface. The presence and distribution of sulfate and $\mathrm{Cr}$ could be detected by Mapping as shown in Fig. 4. Mapping results presented that sulfate on $\mathrm{ZrO}_{2}$ and $\mathrm{Cr}$ on $\mathrm{SZ}$ could be distributed evenly on the surface. It indicated that sulfate and $\mathrm{Cr}$ were successfully impregnated on $\mathrm{ZrO}_{2}$.

TEM images of $\mathrm{ZrO}_{2}, \mathrm{SZ}, \mathrm{Cr} 1 / \mathrm{SZ}, \mathrm{Cr} 2 / \mathrm{SZ}$, and $\mathrm{Cr} 3 / \mathrm{SZ}$ catalysts are presented in Fig. 5. TEM results also showed the presence of particle agglomeration after the addition of sulfate and $\mathrm{Cr}$ which could be caused by heat treatment [10]. It also showed that there were no visible metallic $\mathrm{Cr}$ aggregates. The black areas might represent groups of the accumulated particles [25]. However, this observation also exhibited the morphology of the catalysts with different sizes and disordered shapes for each catalyst.

\section{Catalyst Activity and Selectivity}

Fig. 6 shows an IR spectrum of the plastic waste used in this study. IR spectrum was taken in the range of 4000$500 \mathrm{~cm}^{-1}$. The results show that the absorption bands at 2924 and $2855 \mathrm{~cm}^{-1}$ were attributed to the stretching vibration of the $\mathrm{C}-\mathrm{H}$ bond. The absorption band at $1458 \mathrm{~cm}^{-1}$ corresponds to the bending vibration of $\mathrm{CH}_{2}$ [26]. The absorption band at $1373 \mathrm{~cm}^{-1}$ was assignable to the bending vibration of $\mathrm{CH}_{3}$, exhibiting the characteristic of LDPE [27]. The absorption bands at around $730-717 \mathrm{~cm}^{-1}$ were attributed to the rocking vibration of $\mathrm{CH}_{2}$. The result of this characterization strengthened the type of plastic used in this study.

The effect of temperature in the hydrocracking process over $\mathrm{Cr} 2 / \mathrm{SZ}$ catalyst is shown in Table 1 . It can be seen that the higher temperature used in the hydrocracking

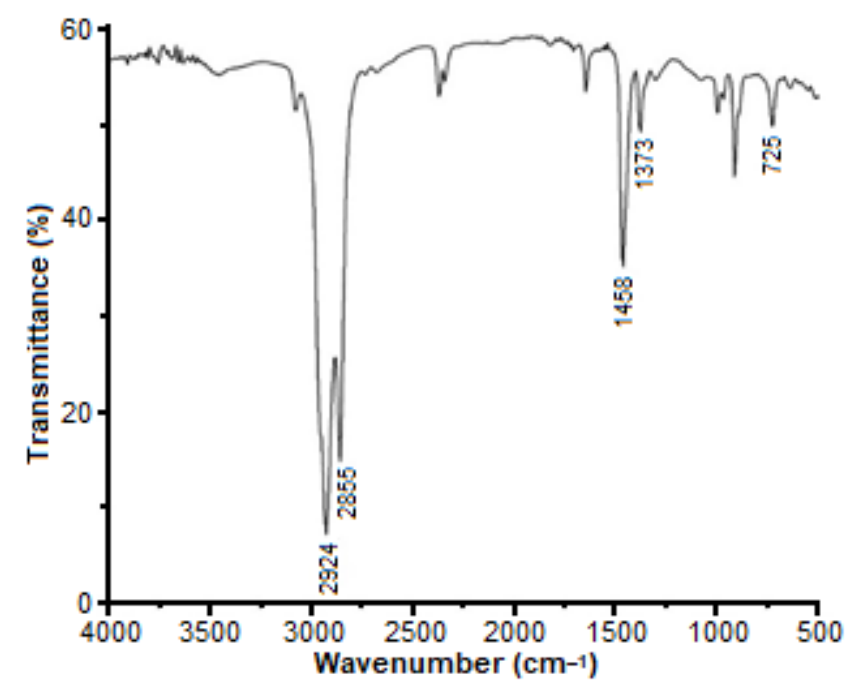

Fig 6. IR spectrum of LDPE-based plastic waste

Table 1. Products for hydrocracking of LDPE-based plastic waste over $\mathrm{Cr} 2 / \mathrm{SZ}$

\begin{tabular}{lccc}
\hline \multirow{2}{*}{ Temperature $\left({ }^{\circ} \mathrm{C}\right)$} & \multicolumn{3}{c}{ Yield (wt.\%) } \\
\cline { 2 - 4 } & Liquid & Coke & Gas \\
\hline 250 & 40.99 & 0.01 & 59.00 \\
300 & 30.13 & 0.55 & 69.32 \\
350 & 11.43 & 0.93 & 87.65 \\
\hline
\end{tabular}


process the fewer the liquid product. The higher temperature caused the higher formation of the coke and gas produced. This can be proven by seeing the yield of the coke and gas at the highest temperature level, which were 0.93 and $87.65 \%$, respectively. It can be assumed that the coke that was produced covered the active sites of the catalyst thus it lowered the formation of the liquid product [31]. Based on the results, it was concluded that the effective temperature for the hydrocracking of LDPE was $250{ }^{\circ} \mathrm{C}$. The selectivity in liquid products at various temperatures is presented in Fig. 7. It shows that the higher temperature used in the hydrocracking process could decrease the selectivity for gasoline fractions and instead increase that of diesel.

The hydrocracking of LDPE-based plastic waste was conducted in the presence of $\mathrm{ZrO}_{2}$, SZ, Cr1/SZ, Cr2/SZ, and $\mathrm{Cr} 3 / \mathrm{SZ}$ as catalyst. The yields of products for various catalysts are summarized in Table 2. It can be seen from the table that the presence of sulfate and $\mathrm{Cr}$ on $\mathrm{ZrO}_{2}$ could increase the yields of the liquid products. The high yield of the liquid products can be brought by the catalyst acidity. The impregnation of sulfate on $\mathrm{ZrO}_{2}$ and that of $\mathrm{Cr}$ on SZ can increase the acidity because of the contribution of Brønsted and Lewis acid sites. Variations in metal concentrations in the SZ catalyst also gave the difference in the liquid products in which the highest metal concentration could reduce the liquid product. As reported in a previous research [24], the acidity of catalysts is also decreased by the modification of excess metal to SZ. The acidity values of the catalysts was the smallest with the highest metal concentration. This factor certainly could influence the decreasing catalytic activity in the highest metal concentration. The highest liquid product was obtained by $\mathrm{Cr} 2 / \mathrm{SZ}$ catalyst, being $40.99 \%$. The table also shows the decrease of solid products by the presence of $\mathrm{Cr}$ on SZ. Modification of SZ with Cr has been proven to reduce coke formation, preventing the deactivation of the catalyst as discussed before. Catalytic hydrocracking proceeds through a carbonium ions mechanism [28]. Carbonium ions could be formed by the interaction of olefins with acidic sites. This stage was stated as the initiation stage. This stage could also occur for paraffin compounds that lost a hydride ion [29]. Sie reported a new

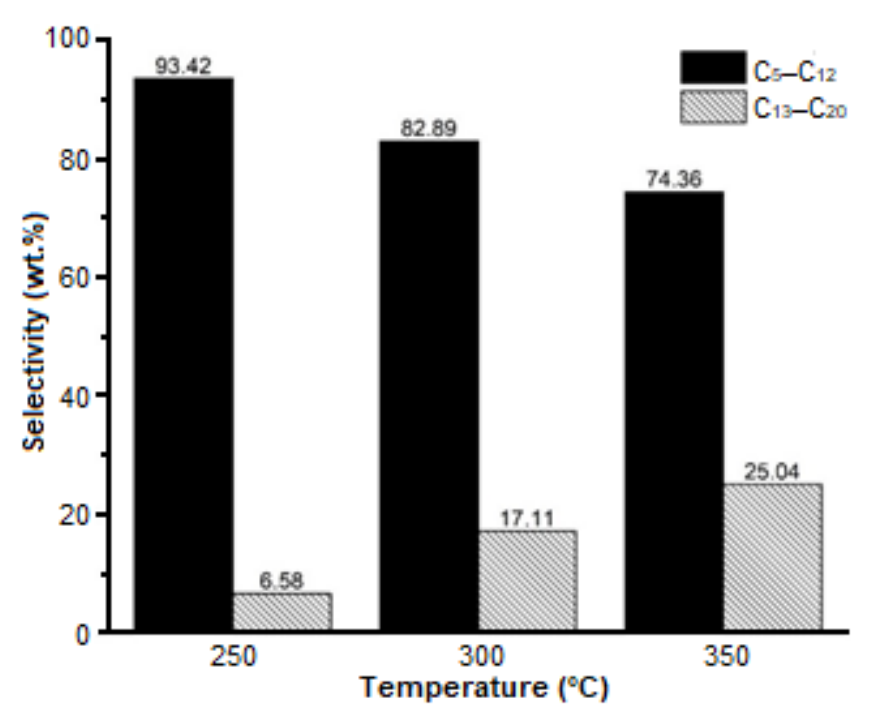

Fig 7. Selectivity in liquid products over $\mathrm{Cr} 2 / \mathrm{SZ}$ at various temperatures

Table 2. Products for hydrocracking of LDPE-based plastic waste over various catalysts at $250{ }^{\circ} \mathrm{C}$

\begin{tabular}{lccc}
\hline \multirow{2}{*}{ Catalyst } & \multicolumn{3}{c}{ Yield (wt.\%) } \\
\cline { 2 - 4 } & Liquid & Coke & Gas \\
\hline $\mathrm{ZrO}_{2}$ & 17.39 & 0.36 & 82.25 \\
$\mathrm{SZ}$ & 28.72 & 0.34 & 70.94 \\
$\mathrm{Cr} 1 / \mathrm{SZ}$ & 33.48 & 0.01 & 66.51 \\
$\mathrm{Cr} 2 / \mathrm{SZ}$ & 40.99 & 0.01 & 59.00 \\
$\mathrm{Cr} 3 / \mathrm{SZ}$ & 37.51 & 0.01 & 62.48 \\
\hline
\end{tabular}

mechanism for paraffin cracking over acid catalysts [30]. Such activated paraffin hydrocarbons undergo rearrangement to produce protonated cyclopropane ions (with a more stable state than their linear form). The carbonium intermediates were protonated with hydrogen and broken down into short chains of branched hydrocarbons (gasoline fraction) and long chains of straight hydrocarbons (diesel fractions). Carbonium intermediate with an increasing number of carbon atoms would crack more easily.

The selectivity values in the liquid product for the hydrocracking of LDPE waste over all catalysts are shown in Fig. 8. All of the catalysts showed that the selectivity for the gasoline fraction was higher than that of diesel. However, the presence of sulfate and $\mathrm{Cr}$ on $\mathrm{ZrO}_{2}$ could increase the selectivity towards the gasoline fraction $\left(\mathrm{C}_{5}\right.$ $\left.\mathrm{C}_{12}\right)$ and decrease that of the diesel fraction $\left(\mathrm{C}_{13}-\mathrm{C}_{20}\right)$, representing the desired result. The highest selectivity for 


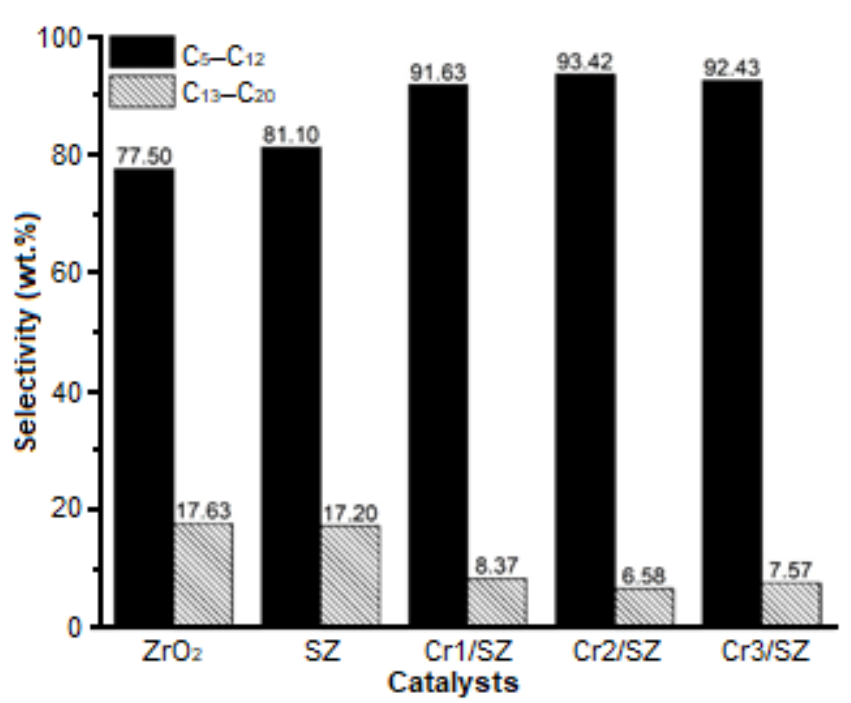

Fig 8. Selectivity in liquid products over various catalysts

Table 3. Products of LDPE waste hydrocracking over reused $\mathrm{Cr} 2 / \mathrm{SZ}$

\begin{tabular}{lccc}
\hline \multirow{2}{*}{ Catalyst } & \multicolumn{3}{c}{ Yield (wt.\%) } \\
\cline { 2 - 4 } & Liquid & Coke & Gas \\
\hline Fresh & 40.99 & 0.01 & 59.00 \\
$1^{\text {st }}$ reuse & 32.71 & 0.02 & 67.28 \\
$2^{\text {nd }}$ reuse & 32.54 & 0.11 & 67.35 \\
$3^{\text {rd }}$ reuse & 30.93 & 0.17 & 68.90 \\
\hline
\end{tabular}

the gasoline fraction, which was $93.42 \%$, was obtained over the Cr2/SZ catalyst.

The results of the repeated use of $\mathrm{Cr} 2 / \mathrm{SZ}$ for the hydrocracking of LDPE are given in Table 3. The results show that the liquid products decreased gradually with the repeated use, but the Cr2/SZ catalyst was still active even after three repetitions. The yield of the solid products were also getting higher as a result of the reuse. The selectivity values are presented in Fig. 9. The used Cr2/SZ catalyst for hydrocracking was also able to decrease the selectivity to gasoline fraction and increase that of the diesel fraction, because of the formation of high yields of solid products due to the non optimal condition of the plastic cracking process.

\section{- CONCLUSION}

The morphology of the prepared catalysts with the addition of sulfate and $\mathrm{Cr}$ showed the different sizes and disordered shapes of the catalysts. The effective temperature for hydrocracking was demonstrated to be

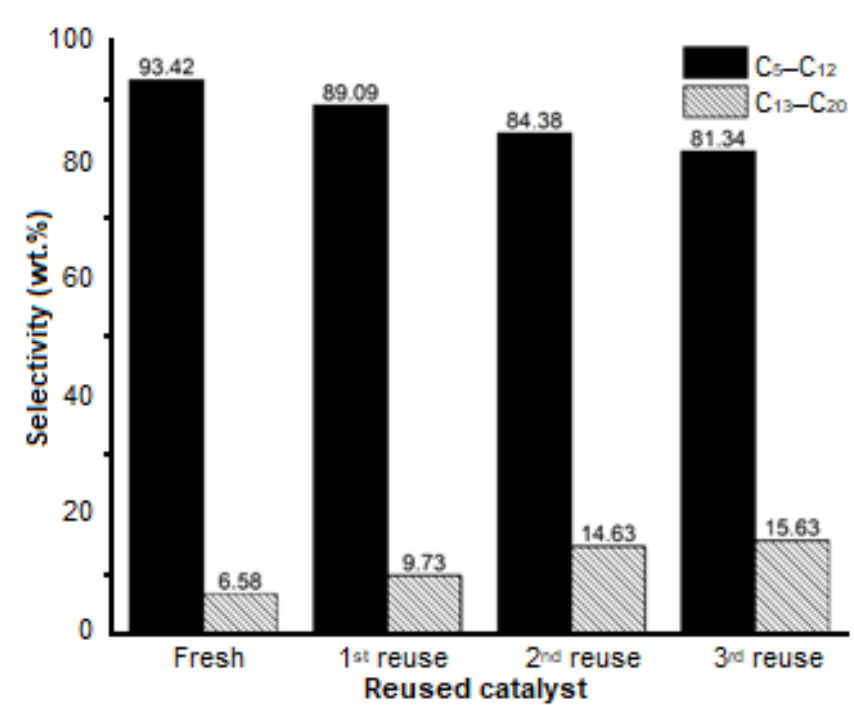

Fig 9. Selectivity in liquid products over reused Cr2/SZ

$250{ }^{\circ} \mathrm{C}$ and the result also showed that the higher temperature in the hydrocracking process could decrease the selectivity for the gasoline fractions and instead increase that of diesel. The highest liquid product and gasoline fraction selectivity were obtained over Cr2/SZ, being 40.99 and 93.42 wt.\%, respectively. $\mathrm{Cr} 2 / \mathrm{SZ}$ catalyst was stable and reusable up to three repetitions.

\section{- ACKNOWLEDGMENTS}

The authors thank the Ministry of Research and Higher Education of Indonesia which had financially supported this research under the Scholarship Program of PMDSU Batch II with contract number: 2028/UN1/DITLIT/DIT-LIT/LT/2018.

\section{- REFERENCES}

[1] Sriningsih, W., Saerodji, M.G., Trisunaryanti, W., Armunanto, R., and Falah, I.I., 2014, Fuel production from LDPE plastic waste over natural zeolite supported $\mathrm{Ni}, \mathrm{Ni}-\mathrm{Mo}$, Co and Co-Mo metals, Procedia Environ. Sci., 20, 215-224.

[2] Sarker, M., Rashid, M.M., Rahman, M.S., and Molla, M., 2012, Environmentally harmful low density waste plastic conversion into kerosene grade fuel, J. Environ. Prot., 3 (8), 700-708.

[3] Burange, A.S., Gawande, M.B., Lam, F.L.Y., Jayaram, R.V., and Luque, R., 2015, 
Heterogeneously catalyzed strategies for the deconstruction of high density polyethylene: Plastic waste valorisation to fuels, Green Chem., 17 (1), 146156.

[4] Fatimah, I., Wijaya, K., and Setyawan, K.H., 2008, Synthesis $\mathrm{ZrO}_{2}$-montmorillonite and application as catalyst in catalytic cracking of heavy fraction of crude oil, Bull. Chem. React. Eng. Catal., 3 (1-3), 9-13.

[5] Zhao, J., Yue, Y., Hua, W., He, H., and Gao, Z., 2007, Catalytic activities and properties of sulfated zirconia supported on mesostructured $\gamma-\mathrm{Al}_{2} \mathrm{O}_{3}, A p p l$. Catal., A, 336 (1-2), 133-139.

[6] Hasanudin, Said, M., Faizal, M., Dahlan, M.H., and Wijaya, K., 2012, Hydrocracking of oil residue from palm oil mill effluent to biofuel, Sustainable Environ. Res., 22 (6), 395-400.

[7] Suseno, A., Wijaya, K., Trisunaryanti, W., and Shidiq, M., 2015, Synthesis and characterization of $\mathrm{ZrO}_{2}$-pillared bentonites, Asian J. Chem., 27 (7), 2619-2623.

[8] Yu, S., Jiang, P., Dong, Y., Zhang, P., Zhang, Y., and Zhang, W., 2012, Hydrothermal synthesis of nanosized sulfated zirconia as an efficient and reusable catalyst for esterification of acetic acid with n-butanol, Bull. Korean Chem. Soc., 33 (2), 524-528.

[9] Heshmatpour, F., and Aghakhanpour, R.B., 2012, Synthesis and characterization of superfine pure tetragonal nanocrystalline sulfated zirconia powder by a non-alkoxide sol-gel route, Adv. Powder Technol., 23 (1), 80-87.

[10] Said, A.E.A., El-Wahab, M.M.A., and El-Aal, M.A., 2014, Chemical the catalytic performance of sulfated zirconia in the dehydration of methanol to dimethyl ether, J. Mol. Catal. A: Chem., 394, 40-47.

[11] Patel, A., Brahmkhatri, V., and Singh, N., 2013, Biodiesel production by esterification of free fatty acid over sulfated zirconia, Renewable Energy, 51, 227-233.

[12] Wang, P., Zhang, J., Wang, G., Li, C., and Yang, C., 2016, Nature of active sites and deactivation mechanism for $n$-butane isomerization over alumina-promoted sulfated zirconia, J. Catal., 338, 124-134.
[13] Hauli, L., Wijaya, K., and Syoufian, A., 2019, Hydrocracking of LDPE plastic waste into liquid fuel over sulfated zirconia from a commercial zirconia nanopowder, Orient. J. Chem., 35 (1), 128-133.

[14] Jiang, K., Tong, D., Tang, J., Song, R., and Hu, C., 2010, The Co-promotion effect of Mo and $\mathrm{Nd}$ on the activity and stability of sulfated zirconia-based solid acids in esterification, Appl. Catal., A, 389 (12), 46-51.

[15] Saravanan, K., Tyagi, B., Shukla, R.S., and Bajaj, H.C., 2016, Solvent free synthesis of methyl palmitate over sulfated zirconia solid acid catalyst, Fuel, 165, 298-305.

[16] Reddy, B.M., and Patil, M.K., 2009, Organic syntheses and transformations catalyzed by sulfated zirconia, Chem. Rev., 109 (6), 2185-2208.

[17] Subbarao, E.C., Maiti, H.S., and Srivastava, K.K., 1974, Martensitic transformation in zirconia, Phys. Status Solidi A, 21 (1), 9-40.

[18] Utami, M., Wijaya, K., and Trisunaryanti, W., 2017, Effect of sulfuric acid treatment and calcination on commercial zirconia nanopowder, Key Eng. Mater., 757, 131-137.

[19] Belskaya O.B., Danilova, I.G., Kazakov, M.O., Gulyaeva, T.I., Kibis, L.S., Boronin, A.I., Lavrenov, V.A., and Likholobov, V.A., 2010, Investigation of active metal species formation in Pd-promoted sulfated zirconia isomerization catalyst, Appl. Catal., A, 387 (1-2), 5-12.

[20] Yadav, G.D., and Nair, J.J., 1999, Sulfated zirconia and its modified versions as promising catalysts for industrial processes, Microporous Mesoporous Mater., 33 (1-3), 1-48.

[21] Utami, M., Wijaya, K., and Trisunaryanti, W., 2018, Pt-promoted sulfated zirconia as catalyst for hydrocracking of LDPE plastic waste into liquid fuels, Mater. Chem. Phys., 213, 548-555.

[22] Amin, A.K., Wijaya, K., and Trisunaryanti, W., 2018, The catalytic performance of $\mathrm{ZrO}_{2}-\mathrm{SO}_{4}$ and $\mathrm{Ni} / \mathrm{ZrO}_{2}-\mathrm{SO}_{4}$ prepared from commercial $\mathrm{ZrO}_{2}$ in hydrocracking of LDPE plastic waste into liquid fuels, Orient. J. Chem., 34 (6), 3070-3078. 
[23] Hauli, L., Wijaya, K., and Armunanto, R., 2018, Preparation and characterization of sulfated zirconia from a commercial zirconia nanopowder, Orient. J. Chem., 34 (3), 1559-1564.

[24] Hauli, L., Wijaya, K., and Armunanto, R., 2019, Preparation of $\mathrm{Cr}$ metal supported on sulfated zirconia catalyst, Mater. Sci. Forum, 948, 221-227.

[25] Aboul-Gheit, A.K., Gad, F.K., Abdel-Aleem, G.F., and El-Desouki, D.S., 2014, Pt, Re and Pt-Re incorporation in sulfated zirconia as catalysts for $\mathrm{n}$ pentane isomerization, Egypt. J. Pet., 23 (3), 303-314.

[26] Asensio, R.C., Moya, M.S.A., de la Roja, J.M., and Gómez, M., 2009, Analytical characterization of polymers used in conservation and restoration by ATR-FTIR spectroscopy, Anal. Bioanal. Chem., 395 (7), 2081-2096.

[27] Jung M.R., Horgen, F.D., Orski, S.V., Rodriguez, C.V., Beers, K.L., Balazs, G.H., Jones, T.T., Work, T.M., Brignac, K.C., Royer, S.J., Hyrenbach, K.D., Jensen, B.A., and Lynch, J.M., 2018, Validation of ATR FT-IR to identify polymers of plastic marine debris, including those ingested by marine organisms, Mar. Pollut. Bull., 127, 704-716.

[28] Trisunaryanti, W., Armunanto, R., Hastuti, L.P., Ristiana, D.D., and Ginting, R.V., 2018, Hydrocracking of a-cellulose using $\mathrm{Co}, \mathrm{Ni}$, and $\mathrm{Pd}$ supported on mordenite catalysts, Indones. J. Chem., 18 (1), 166-172.

[29] Buekens, A.G., and Huang, H., 1998, Catalytic plastics cracking for recovery of gasoline-range hydrocarbons from municipal plastic wastes, Resour. Conserv. Recycl., 23 (3), 163-181.

[30] Sie, S.T., 1992, Acid-catalyzed cracking of paraffinic hydrocarbons. 1. Discussion of existing mechanisms and proposal of a new mechanism, Ind. Eng. Chem. Res., 31 (8), 1881-1889.

[31] Pongsendana, M., Trisunaryanti, W., Artanti, F.W., Falah, I.I., and Sutarno, 2017, Hydrocracking of waste lubricant into gasoline fraction over CoMo catalyst supported on mesoporous carbon from bovine bone gelatin, Korean J. Chem. Eng., 34 (10), 2591-2596. 